interior of the supercontinent where they suppose that the influence of moisture-bearing wind currents could not reach. And no moisture means, of course, no glaciation. Similarly with coal deposits. Coal apparently can only form in areas where the minimum annual rainfall is $1,500-2,000 \mathrm{~mm}$; and yet coal is found in the interior of Gondwanaland. The obvious conclusion then, according to Meyerhoff and Teichert, is that Gondwanaland could not have existed in the late Carboniferous and Permian. This contention is also supported by the presence of marine evaporites in Gondwanaland's interior within $15^{\circ}$ of the Carboniferous and Permian poles. Although they do not say so explicitly, Meyerhoff and Teichert's position apparently conceals an anti-continental drift philosophy or at least one which does not allow ancient supercontinents.

It is the view of Meyerhoff and Teichert that a revolution in the concepts of southern hemisphere glaciation has been taking place simultaneously with the revolution in the Earth sciences but that the Earth scientists have been too busy to notice it--and thus one of the props of the new global tectonics has been whipped away. Clearly this is to overestimate the importance of glaciation in the continental drift context. Until Gough's recent article appeared the concept of the large Gondwanaland ice sheet was largely of historical interest. important at a time when evidence for drift was sparse but later superseded by far more convincing evidence. This apart, however, it would seem that the conflict between Meyerhoff and Teichert on the one hand and Gough on the other is essentially one of apparent irreconcilability of different disciplines

-palaeontology and geology versus geophysics.

In his reply Gough wryly admits that "as a geophysicist, [he is] an outsider in these geological matters", but nevertheless proceeds to demolish his critics with the confidence of somebody who firmly believes in seeing wood for trees. Thus the existence of the thirty centres of glaciation in their respective positions leads him, with du Toit, to the interpretation that large ice sheets existed over part of Gondwanaland and not to Meyerhoff and Teichert's negative conclusion. The mountain-top ice caps and U-shaped valleys are easy to explain because if ice forms at all in a continent of rugged topography it will do so first on mountain tops. The resulting glaciers would thereby produce radial U-shaped valleys and, if rainfall and freezing continued, possibly continuous ice sheets. Thus the ice movement would be relatively inhibited such that few permanent traces of ice action would be left in the lowlands.

As for the question of rainfall in the
Gondwanaland interior, Gough takes the view that Meyerhoff and Teichert are formulating the problem the wrong way round. The starting point must be the existence of Gondwanaland, evidence for which is now overwhelming. The global tectonic evidence was not mentioned by Meyerhoff and Teichert. The presence of interior ice caps does not disprove the reality of Gondwanaland but only the idea that interior rainfall is impossible. The real problem therefore is to decide how, and under what conditions, the interior ice caps formed. In any case it is not clear to Gough that rainfall cannot occur far from continental margins as long as there is suitable topographical relief.

But there is a final irony. In his original article Gough considered for simplicity a continuous ice sheet $2 \mathrm{~km}$ thick and $3,000 \mathrm{~km}$ in diameter. The fact is that the same mass of ice distributed in lumps over the same area

\section{Advances in Calcitonin Research}

A RENAISSANCE in calcium metabolism research has taken place since the discovery of calcitonin nine years ago. Underlying this effort is the interest in the treatment of some fifty million people in the world today with bonelosing diseases. These diseases are loosely referred to as "osteoporosis".

The current investigative approach to the treatment of bone loss is the use of substances that inhibit bone resorption. The most popular of these is calcitonin, a hormone from the thyroid. Calcitonin acts directly and immediately on osteoclasts, the cells which resorb bone to inhibit their action. Because bone is constantly undergoing remodelling and replacement, prevention of bone loss, while new bone is continuing to be laid down, should lead to more bone. In next Wednesday`s Nature New Biology, two letters or not this hormone will prove of therapeutic importance.

The first of these contributions, by Anderson and his colleagues in Urbana, Illinois, reports the failure of moderately long-term treatment with porcine calcitonin to alter the retention of strontium-85. This isotope is unique in that its uptake in and release from bone is similar to that of calcium. Anderson et al. have measured whole body retention in dogs of this isotope, as a function of bone mineral turnover, and found that calcitonin did not delay its loss. The results are surprising in view of work done elsewhere (for example at the Hammersmith Hospital, London), which has demonstrated that calcitonin increases metaphyseal bone in rats and promotes positive calcium contribute to the discussion of whether will produce the same stresses except very near the surface. Thus a continuous ice sheet is not necessary at all! Moreover, an ice sheet $2 \mathrm{~km}$ thick and only $1,000 \mathrm{~km}$ in diameter will produce the same stresses in the lithosphere and the same stresses below its centre but at a lower depth. Thus the smaller sheet actually produces greater stresses in the asthenosphere where the tectonic flow takes place.

This whole argument, of course, is indicative of the sort of exchange which is likely to become increasingly common. The fact is that the revolution in the Earth sciences has been based almost completely upon geophysics, and many geologists feel that their discipline has not always received the consideration it deserves. The job now is to reinterpret several hundred years of geology in terms of the new global framework; and some friction is only to be expected. in patients with Paget's disease. In contrast to both growing rats and Pagetic patients who have a rapid rate of bone turnover, bone turnover in normal dogs, however, is less and therefore more closely approximates the rates observed in osteoporosis in man. If the observations reported in next week's issue are true, it may be that calcitonin will not prove effective in preventing bone loss in patients whose rates of bone resorption are not abnormally high.

But in a second letter, Potts and his group at the Massachusetts General Hospital in Boston report that salmon calcitonin is $20-2,000$ times more potent than the porcine hormone used in the previous study. Two explanations for this difference are tenable: either the salmon hormone has a greater affinity for receptor sites or it is more resistant to degradation. Potts et al. present evidence which supports the second explanation. As measured by radioimmunoassay, salmon calcitonin was found to have a slower rate of disappearance in the dog.

Salmon and porcine calcitonin differ in fifteen of their constituent aminoacids. That the hormones from different species have different rates of destruction introduces a new concept. This concept seems to be as follows: the activity of a peptide hormone is dependent not only on those aminoacids which confer biological activity but also possibly on other amino-acids which affect its rate of destruction. It follows from this that synthetic analogues which further delay degradation may lead to even more potent preparations than are found in nature. 